Article

\title{
Evaluation of Wedge-Block Concrete Beams Reinforced with EBR-CFRP Laminates by Modified ACI 440.2R-2017 Guide
}

\author{
Ali A. Abdulhameed ${ }^{1, *}$ and AbdulMuttalib I. Said ${ }^{2}$ \\ 1 Department of Reconstruction and Projects, University of Baghdad, Baghdad, Iraq \\ 2 Civil Engineering Department, College of Engineering, University of Baghdad, Iraq \\ * Correspondence: aliadel@uobaghdad.edu.iq
}

\begin{abstract}
Concrete beams built from individual segments connected to each other by special mechanism referred as segmental beam. The aim of this research is to exhibit a new technique for fabrication of small scale segmental beams from wedge shape unreinforced concrete segments and pultruded carbon fiber reinforced polymers (CFRP) in laminate form. Eight segmental beams including two parameters are tested experimentally. The first parameter is the area of CFRP and second is the adhesive material used to bond segments of the beams. The test shows that segmental beams have a higher ratio of CFRP area undergoes less deflection and sustain higher ultimate loading value of $38.4 \%$. Moreover, the test of beams with concrete segments adhered by epoxy resin sustain a higher load than segments adhered by cementitious materials about $11.87 \%$. Theoretically, segmental beams were analyzed by modified American Concrete Institute ACI 440.2R-17 report with slight modifications. The analysis results in an overestimation of flexural strength of segmental beams when compared with experimental outcomes.
\end{abstract}

Keywords: segmental beams; cementitious adhesive; epoxy resin; CFRP laminates; ACI 440.2R-17 procedure

\section{Introduction}

Segmental beams are fabricated in two methods according to either the structural application or their purposes. First method by casting concrete cast-in-situ in individual molds and the other one used precast prestress concrete segments. Segmental construction by precast units has numerous features. In segmental construction, the quality of concrete is ensured, less working loads during construction phases in the site, increase the speed of construction, and alleviate environmental effects which were stated by Li, et.al in [1]. Saibabu, et.al in [2] clarified that large scale segmental beams are used for the construction of bridges overall the world. In practice, segmental beams may be straight or curved aligned, and they are fast, flexible, high quality, and economical construction technique as indicate by Saibabu, et.al in [3]. Type of interface joint between individual segments, quality of joints, and mechanical interlock between segments will affect the behavioral performance of segmental bridges as marked by Saibabu, et.al in [2].

Expanded use of advanced composites materials in many fields in the past few decades due to perfect mechanical engineering properties like high tensile strength, low-density values, and resistance to fatigue [4-6]. Composite materials are currently one of the extremely proper and functional strengthening and reinforcement solutions for upgrading and repair structural elements. Codispoti, et.al in [7] stated that at the same time, with the advance development of construction, it is required to eliminate problems relating to environmental collaboration and bring materials durable and compatible with the substrate concrete. Flexural members like reinforced concrete beams are effectively upgraded, strengthened, and repaired by Externally Bonded - Carbon Fiber Reinforced Polymers (EBR-CFRP) composites. Many causes leads to structural strengthening like deterioration, end of design life, change in the structural function, damaged by mechanical actions, inadequate or 
design errors. Nnumerous researches including practical applications studied several methods for structural strengthening; one of the most efficient methods is the strengthening by EBR-CFRP laminates as mentioned by Toutanji, et.al in [8].

The American Concrete Institute report ACI 440.2R-17 [9] presents a guide for design and construction of Fiber reinforced Polymer (FRP) systems for strengthening concrete structures. The purpose of this guide is to display general information on the use and history of FRP system as a strengthening material. Furthermore, the guide presents recommendations on the engineering, construction, and inspection for FRP used in structural strengthening especially reinforced concrete structures. ACI 440.2R-17 guide is basically based on the gained knowledge from experimental researches, analysis, and practical application of FRP composite system used for structural strengthening.

\section{Research Significance}

In this research, a new construction method for short segmental beams is developed. Employment of CFRP laminates as an externally bonded flexural reinforcement and wedge-shape unreinforced concrete blocks for manufacturing eight short-span segmental beams. Design procedure developed in the guide of ACI 440.2R-17 was modified to be applicable for segmental beams. Moreover, full analysis of segmental beams according to the modified procedure is illustrated step-by-step in this research.

\section{Experimental Program of the Current Study}

Eight segmental beams fabricated from unreinforced wedge-shape concrete blocks and EBR-CFRP laminates type Sika CarboDur Plates [10] and bonded by epoxy resin type Sikadur-30 LP [11] are tested experimentally until failure. The concrete blocks have specified compressive strength of 30MPa. Each segmental consist of seven individual wedge-shape unreinforced segments with an overall length of $0.9 \mathrm{~m}$. Two of the beams made by adhered concrete blocks interface with cementitious adhesive type Cemfix W [12] and the others made by epoxy resin type Sikadur-31 SBA S-02 [13]. Additionally, two of the beams made by using one ply of CFRP laminates and the other two made by one ply of CFRP but twice the area of CFRP laminates. All of the beams have typical cross-sectional dimensions as they are $200 \mathrm{~mm}$ width and $80 \mathrm{~mm}$ depth. Those dimensions selected to fill-fit the width of walls or columns which is assumed to rest on. Specimen designation system and typical segmental beam layout are shown in Figures 1 and 2; respectively. Concrete blocks, Sika CarboDur Plates, and Sikadur-30 LP mechanical and technical properties which either tested experimentally or obtained from the manufacturer are shown in Tables 1, 2 and 3; respectively.

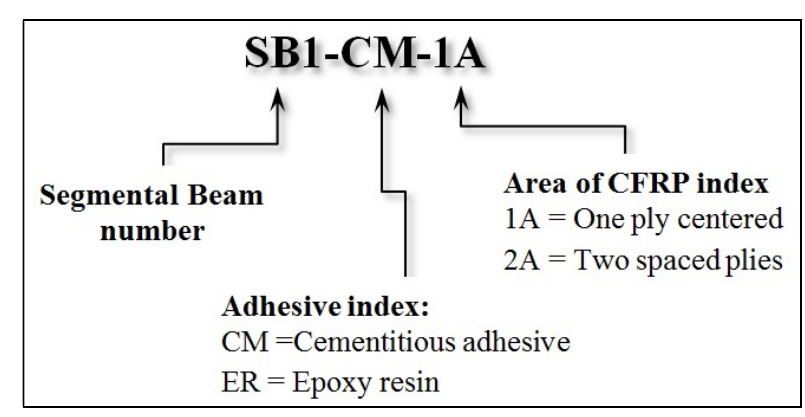

Figure 1. Specimen designation system 


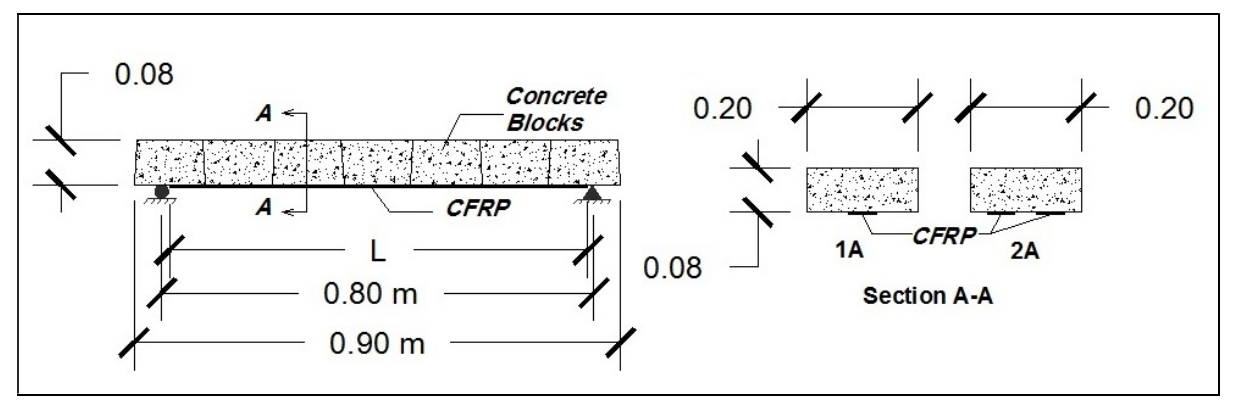

Figure 2. Segmental beam layout

Table 1. Concrete mechanical properties

\begin{tabular}{ccc}
\hline $\begin{array}{c}\text { Mechanical property } \\
\text { Value, MPa }\end{array}$ & Notes \\
\hline $\begin{array}{c}\text { Specified compressive strength } \\
\text { Flexural Strength }\end{array}$ & 28 & $\begin{array}{c}\text { Average compressive strength @28 days for } \\
\text { 3 standard cylinders }\end{array}$ \\
Modulus of Rupture & 24870 & According to ACI 318-14, section 19.2.2.1(b) \\
Modulus of Rupture & 3.9 & Average flexural strength @ 28days for 3 \\
tested prisms
\end{tabular}

Table 2. Sika CarboDur plates technical data [8]

\begin{tabular}{ccccccc}
\hline Width & Thickness & $\begin{array}{c}\text { Density } \\
\left.\text { (at 23 }{ }^{\circ} \mathbf{C}\right)\end{array}$ & $\begin{array}{c}\text { Fiber Volume } \\
\text { Content }\end{array}$ & $\begin{array}{c}\text { Tensile } \\
\text { Strength } \\
\text { (min.) }\end{array}$ & $\begin{array}{c}\text { Modulus of } \\
\text { Elasticity } \\
\text { (min.) }\end{array}$ & $\begin{array}{c}\text { Strain at } \\
\text { break } \\
\text { (min. value) }\end{array}$ \\
\hline $50 \mathrm{~mm}$ & $1.4 \mathrm{~mm}$ & $\begin{array}{c}1.6 \\
\mathrm{~g} / \mathrm{cm} 3\end{array}$ & $>68 \%$ & $>2800 \mathrm{MPa}$ & $\begin{array}{c}>160000 \\
\mathrm{MPa}\end{array}$ & $>1.7 \%$ \\
\hline
\end{tabular}

Table 3. Technical specifications of Sikadur-30 LP epoxy resin [9]

\begin{tabular}{|c|c|c|c|c|c|}
\hline $\begin{array}{c}\text { Chemical } \\
\text { base }\end{array}$ & $\begin{array}{c}\text { Layer } \\
\text { Thickness }\end{array}$ & $\begin{array}{c}\text { Tensile Strength } \\
\text { in Flexure }(1 \text { day } \\
\left.\text { curing },+25^{\circ} \mathrm{C}\right)\end{array}$ & $\begin{array}{c}\text { Modulus of } \\
\text { Elasticity in } \\
\text { Tension } \\
\left(+25^{\circ} \mathrm{C}\right)\end{array}$ & Shrinkage & $\begin{array}{c}\text { Tensile } \\
\text { Adhesion } \\
\text { Strength for } \\
\text { concrete (1 day } \\
\text { curing) }\end{array}$ \\
\hline $\begin{array}{l}\text { Epoxy } \\
\text { resin }\end{array}$ & $\begin{array}{c}30 \mathrm{~mm} \\
\max \end{array}$ & $12 \mathrm{MPa}$ & $\sim 10000 \mathrm{MPa}$ & $\sim 0.04 \%$ & $>4 \mathrm{MPa}$ \\
\hline
\end{tabular}

\subsection{Beams Fabrication}

Beams were fabricated after curing of wedge-blocks for 28 days. The blocks are arranged upside-down in between one and another and adhered at the interface of the blocks by the adhering materials. The beams left for the setting of the adhesive for the proper time according to materials manufacturer instructions. Later on, locating the position of CFRP laminates and then they are installed as shown in Figure 3. The cross-sectional properties for tested small-scale segmental beams are shown in Table 4. In order to obtain wide range of data, two typical beams were fabricated for each of the four studied cases including the cross-sectional area EBR-CFRP laminate and the type of adhesive used for binding concrete blocks. 


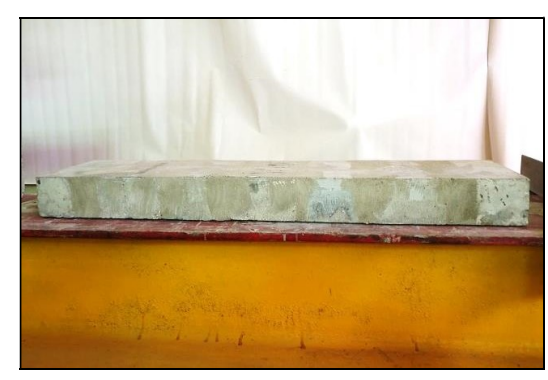

(a) Adhering concrete blocks

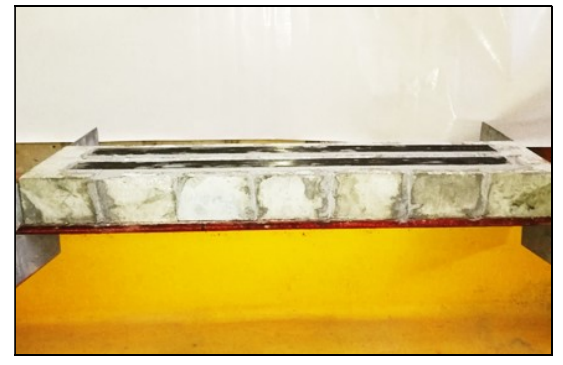

(b) Bonding EBR-CFRP

Figure 3. Fabrication of segmental beams

Table 4. Properties of segmental beams

\begin{tabular}{ccc}
\hline Beam No. & $\begin{array}{c}\text { Cross-sectional } \\
\text { area of EBR CFRP } \\
\text { laminate }(\mathbf{m m})\end{array}$ & $\begin{array}{c}\text { Adhesive } \\
\text { material used }\end{array}$ \\
\hline SB1-CM-1A & 70 & $\begin{array}{c}\text { Cementitious } \\
\text { adhesive } \\
\text { SB2-CM-1A }\end{array}$ \\
SB3-CM-2A & 140 & $\begin{array}{c}\text { Cementitious } \\
\text { adhesive }\end{array}$ \\
SB4-CM-2A & & Epoxy resin \\
SB5-ER-1A & 70 & Epoxy resin \\
SB6-ER-1A & & \\
SB7-ER-2A & 140 & \\
SB8-ER-2A & &
\end{tabular}

\subsection{Experimental Test Setup}

Testing of segmental beams done by subjecting beams to two-point loading spaced $0.6 \mathrm{~m}$ within $0.8 \mathrm{~m}$ clear-spans as shown in Figure 4. The beams were positioned on two simply supports in the testing frame which has an electrical hydraulic loading arm. Load cell with a capacity of 5-ton force was used to measure loading value. Beams deflection under loading measured at both of quarter-span and mid-span by means of two digital indicators ranged $(0-25.4) \mathrm{mm}$ and an accuracy of $0.01 \mathrm{~mm}$. The tensile strain in CFRP plates was measured at both of the ends of the plate and mid-span by means of two strain gauges type BFLA-5-3-3-3LJC manufactured by TML with a gauge length of $5 \mathrm{~mm}$ and transverse sensitivity of (-0.1\%) according to the manufacturer. The compression strain in unreinforced concrete wedge-blocks was also measured at the extreme top fibers at beams mid-span by using strain gauges type PL-60-11-3L manufactured by TML with a gauge length of $60 \mathrm{~mm}$ and transverse sensitivity of $(0.6 \%)$. Campbell Scientific data-logger CR1000 was used to record strain values. Typical test arrangements of segmental beams testing-specimen is shown in Figure 5. 


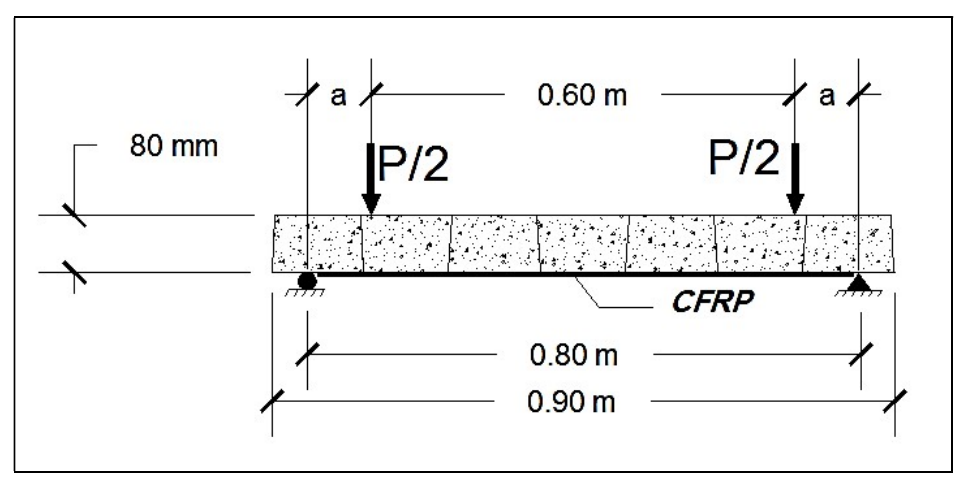

Figure 4. Schematic diagram for segmental beam subjected to loading

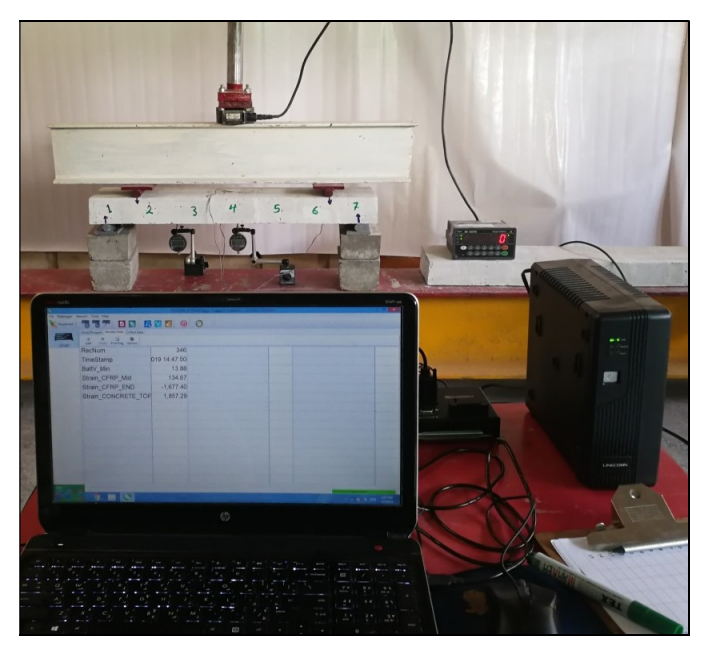

Figure 5. Typical test arrangements of segmental beams specimen

\section{The modified ACI 440.2R-17 Guide for Design and Construction Procedure of FRP Systems}

The application of ACI 440.2R-17 procedure in the design of segmental beams reinforced with EBR CFRP laminates requires two assumptions. The benefits from adopting and modifying the ACI 440.2R-2017 guide are to calculate the ultimate load carrying capacity of segmental beams, and study whether this method can be applied for segmental beams or not. The assumptions are;

- Due to the existence of the adhering material at the interface between adjacent concrete blocks, namely epoxy adhesive or cementitious adhesive, the segmental beams will consider being a monolithic member.

- The failure mode of beams is governed by debonding of CFRP system.

\section{Experimental Results and discussion}

Ultimate carrying capacity loads, the corresponding quarter-span and mid-span beams deflection, and tensile and compression strain results for segmental beams are listed in Table 5 . 
Table 5. Properties of segmental beams

\begin{tabular}{|c|c|c|c|c|c|c|}
\hline \multirow[b]{2}{*}{ Beam No. } & \multirow[b]{2}{*}{$\begin{array}{l}\text { Ultimate } \\
\text { failure } \\
\text { load, KN }\end{array}$} & \multicolumn{2}{|c|}{$\begin{array}{c}\text { Vertical } \\
\text { displacement, } \mathrm{mm}\end{array}$} & \multicolumn{2}{|c|}{$\begin{array}{c}\text { Tensile micro train, } \\
\mathrm{mm} / \mathrm{mm}\end{array}$} & \multirow{2}{*}{$\begin{array}{c}\text { Compression } \\
\text { micro strain } \\
\text { at mid-span, } \\
\mathrm{mm} / \mathrm{mm}\end{array}$} \\
\hline & & $\begin{array}{l}\text { Quarter } \\
\text {-span }\end{array}$ & $\begin{array}{l}\text { Mid- } \\
\text { span }\end{array}$ & $\begin{array}{c}\text { At end of } \\
\text { CFRP } \\
\text { laminates }\end{array}$ & $\begin{array}{c}\text { At } \\
\text { mid-span } \\
\text { in CFRP } \\
\text { laminates }\end{array}$ & \\
\hline SB1-CM-1A & 21.47 & 1.04 & 1.49 & 470.6 & 536.76 & 151.60 \\
\hline SB2-CM-1A & 23.49 & 1.14 & 1.63 & 485.9 & 561.96 & 162.94 \\
\hline SB3-CM-2A & 43.8 & 2.42 & 3.09 & 238.9 & 481.4 & 241.6 \\
\hline SB4-CM-2A & 40.65 & 2.25 & 2.89 & 223.85 & 459.76 & 229.58 \\
\hline SB5-ER-1A & 35.40 & 1.58 & 2.35 & 142.2 & 345.9 & 183.8 \\
\hline SB6-ER-1A & 32.240 & 1.46 & 2.16 & 131.8 & 324.6 & 171.4 \\
\hline SB7-ER-2A & 49.0 & 1.37 & 1.58 & 301.2 & 595.4 & 265.3 \\
\hline SB8-ER-2A & 50.77 & 1.42 & 1.64 & 309.8 & 610.3 & 274.8 \\
\hline
\end{tabular}

From data analysis of Table 5, it is clear that each typical beams (for example SB1-CM-1A and SB2-CM-1A), sustain similar loads, and exhibit similar displacement and strains. According to the aforementioned, the results of one of each typical two beams will be considered in the study. Segmental beams considered in the next sections SB1-CM-1A, SB3-CM-2A, SB5-ER-1A, and SB7-ER-2A.

As the beams made from segments, the possibility of symmetrical failure like monolithic reinforced concrete beams is weak even all beams have symmetrical loading and boundary conditions. Segmental beams specimens failed under loading in a similar manner as shown in Figures 6 and 7 for beams SB1-CM-1A, and SB7-ER-2A; respectively. For specimen SB1-CM-1A, the diagonal-shear crack propagates from the soffit of the beam (at the verge of EBR-laminate in block 7) towards the closest blocks interface followed by debonding of cementitious adhesive. Mode of failure of SB7-ER-2A is different; the diagonal-shear crack propagates in an inclined angle from the soffit of the beam at the verge of EBR-laminate in block 1 crossing the interface with block 2 till failure. The difference in the failure mode of the illustrated specimens is due to the adhering material used for beam fabrication as the tensile strength of epoxy resin is much more than the cementitious adhesive material used in specimen SB1-CM-1A. It is important to mention that no flexural cracks appear in the tested specimens.

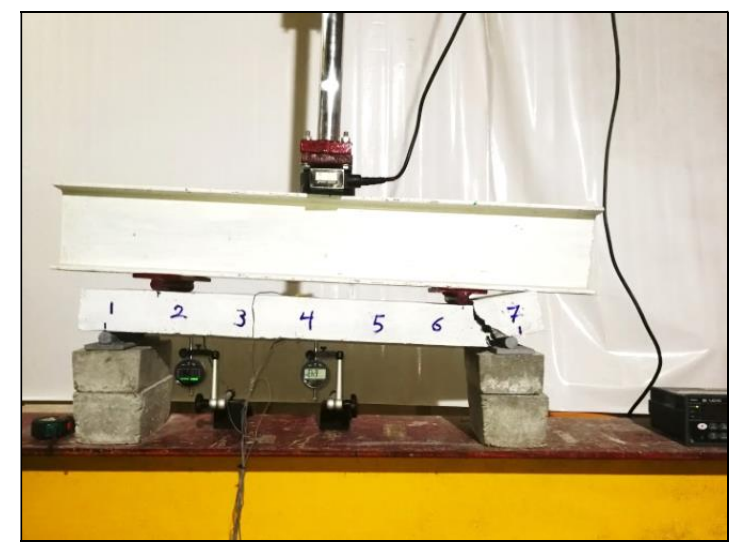

Figure 6. Failure mode of beam SB1-CM-1A 


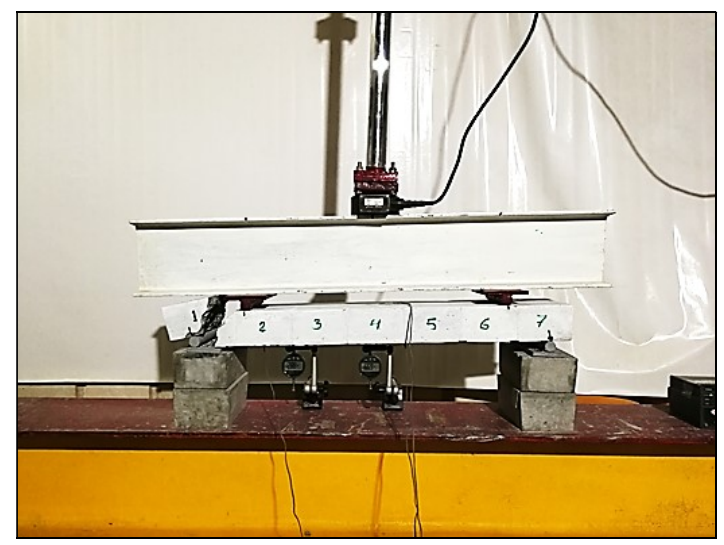

Figure 7. Failure of Beam SB7-ER-2A

The load-displacement curves for all tested beams up to failure loads at both quarter-span and mid-span are shown in Figures 8 and 9, respectively. From these figures, it is obvious that segmental beam SB3-CM-2A shows largest ductile behavior up to failure for both recorded displacements at quarter and mid-span. This is mostly due to response binding cementitious material of the wedge-blocks which allows beams to exhibit elastic behavior than other beams. Segmental beams SB3-CM-2A and SB1-CM-1A fabricated by using similar adhesive but the prior have twice EBR-CFRP laminates area in the cross-section. SB3-CM-2A withstand loading 104\% greater than SB1-CM-1A. Similarly for beams SB7-ER-2A and SB5-ER-1A, the prior beam sustains loading $38.4 \%$ more than SB5-ER-1A. Comparing beams SB1-CM-1A and SB7-ER-2A showed that beam specimen SB7-ER-2A resist $112.5 \%$ loading more than specimen SB1-CM-1A.

Moreover, segmental beam SB7-ER-2A sustains highest loads up to failure among all tested specimens. The only explanation for this behavior is due to the dual action resulted from both the effect of epoxy resin bonding beam wedge-blocks which have considerable tensile stress when compared cementitious adhesive and EBR-CFRP reinforcement ratio.

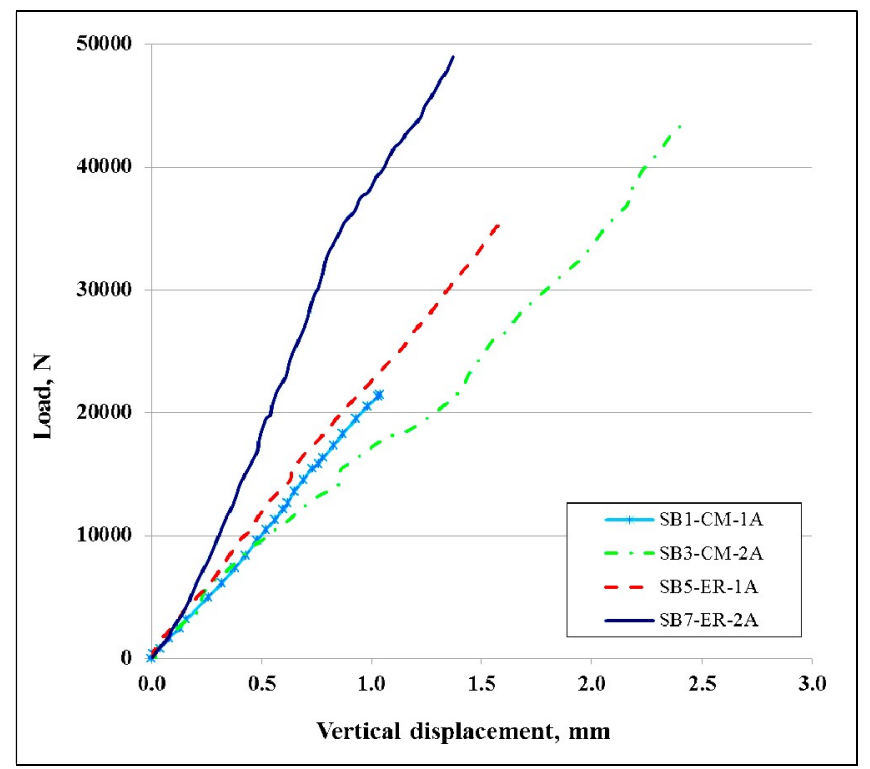

Figure 8. Load vs. vertical displacement of segmental beams at quarter-span

Segmental beams SB3-CM-2A and SB7-ER-2A withstand the greater loading value among tested beams as both beams are typical in sectional properties except for blocks adhesive materials. The ultimate load carried by SB7-ER-2A greater than SB3-CM-2A by $11.87 \%$ while the recorded deflection was less than by $48.86 \%$. Additionally, segmental beam SB1-CM-1A withstands the lower 
flexural strength among all beams which is due to two reasons namely; the weak adhering material, and less reinforcement ratio.

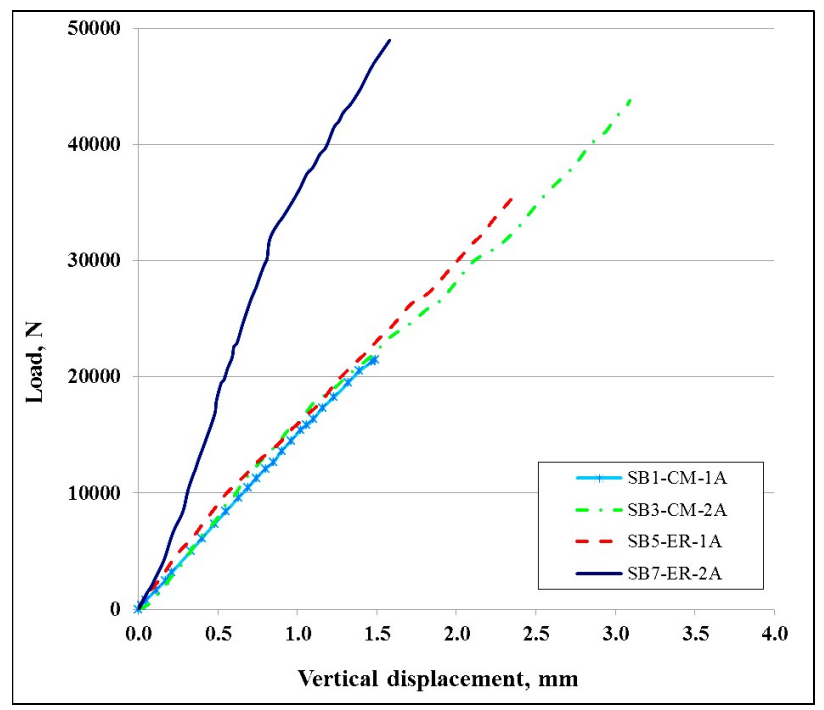

Figure 9. Load vs. vertical displacement of segmental beams at mid-span

The applied loading vs. tensile strain produced by load application in EBR-CFRP laminates at both of beams mid-span and reinforcement end for tested specimens is shown in Figures 10 and 11, respectively. From these curves, it is noticeable that the reinforcement of beam SB1-CM-1A strained greater than other beams at the end-zone of EBR-CFRP laminates as this sample was manufactured using lower reinforcement area and weak cementitious bonding material. The strain values for other specimens are almost the same at the end-zone of EBR-CFRP laminates.

Moreover, strain in extreme compression fibers of beams investigated at mid-span. In Figure 12, it is obvious that segmental beam SB7-ER-2A that withstand loading up to $49 \mathrm{KN}$ is subjected to higher compression strain as the specimen resist flexural bending. However, beam specimen SB3-CM-1A behaved in a similar manner and exhibited $9 \%$ compression strain less than beam specimen SB7-ER-2A at failure loading.

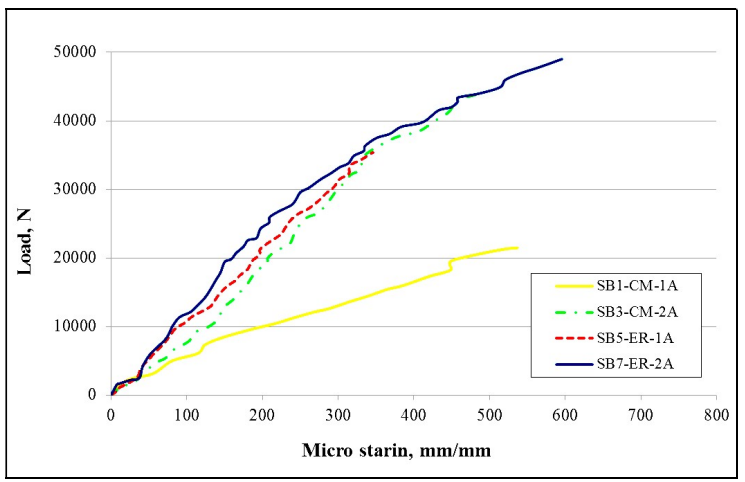

Figure 10. Load vs. tensile strain in EBR-CFRP laminates at mid-span for tested beams 


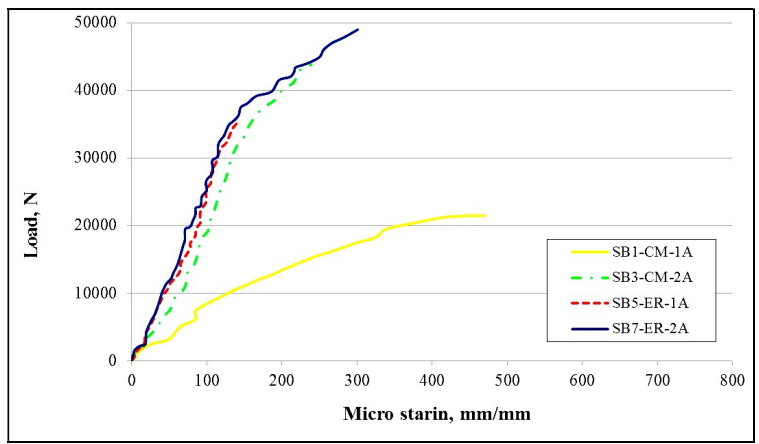

Figure 11. Load vs. tensile strain in EBR-CFRP laminates at end-span for tested beams

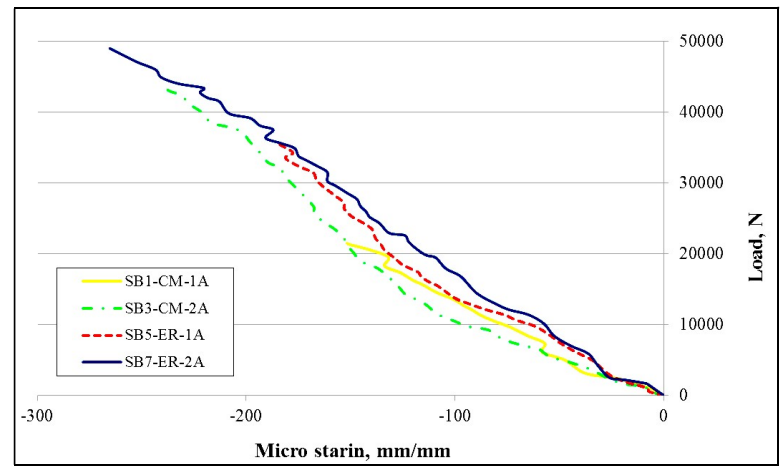

Figure 12. Load vs. compression strain in concrete blocks for beams specimens at mid-span

The hypothetical strain gradient across the depth of beams specimens at mid-span for different loading stages based on measured strains at the extreme tension and compression fibers were shown in Figure 13. It was noticed that the depth of the compression zone decreased during loading progress for all specimens. On the same time, the compression strain and hence the stresses will increases in concrete blocks as the depth of the compression zone decreased. This behaviour was unlike over reinforced traditional flexural member, the depth of the compression zone increased during loading progress. Even-though, the brittle failure mode of tested specimen was similar to over reinforced traditional flexural members [8-9].

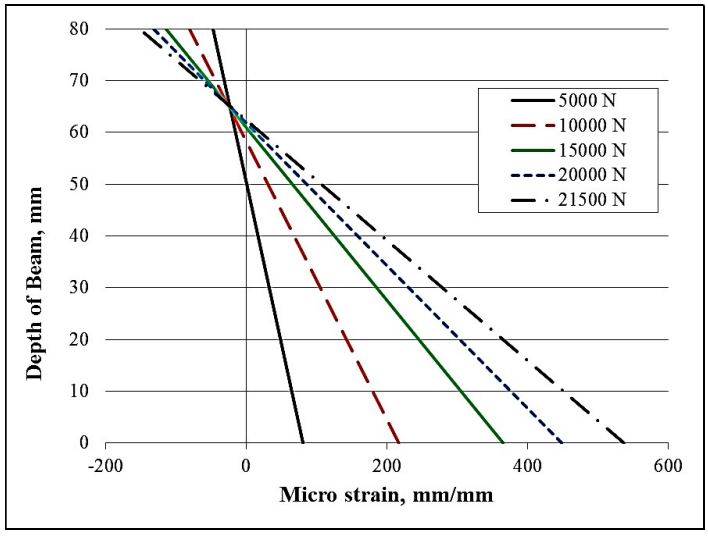

(a)

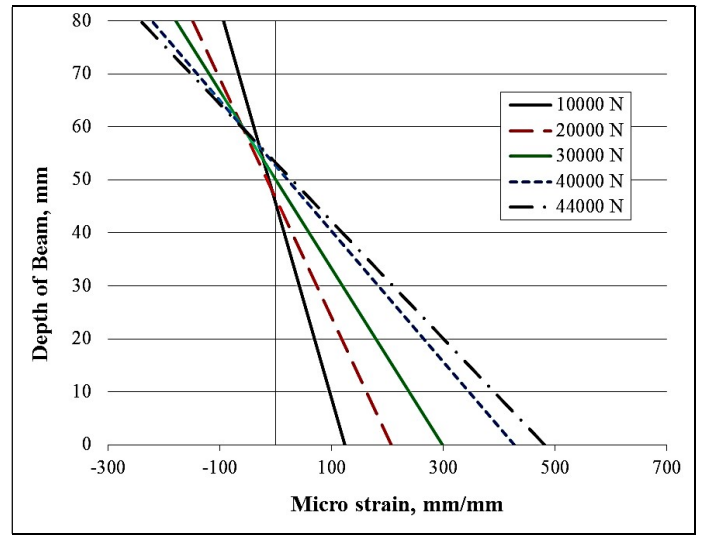

(b) 


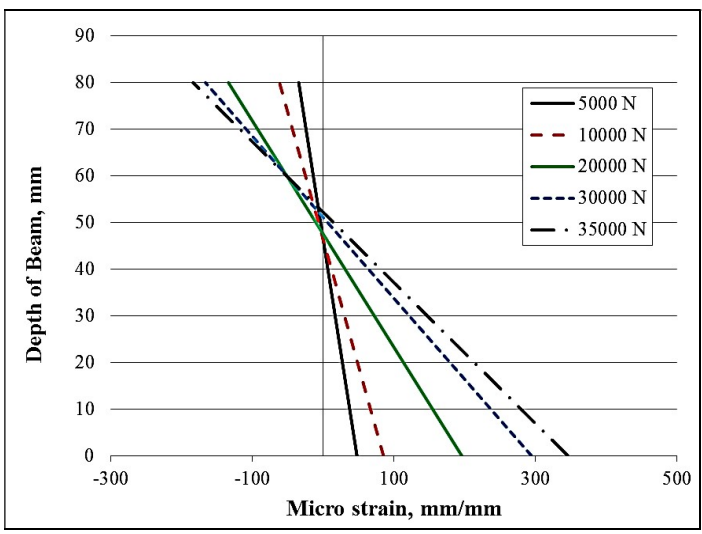

(c)

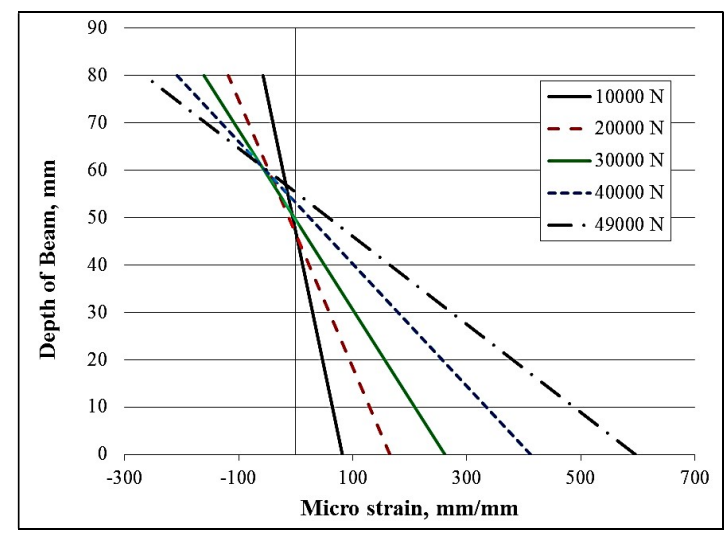

(d)

Figure 13. Strain gradient across the depth of segmental beams: (a) SB1-CM-1A; (b) SB3-CM-2A; (c) SB5-ER-1A; (d) SB7-ER-2A

\section{Verification of modified procedure of ACI 440.2R-2017 Guidelines}

For both cases analyzed of segmental beams SB-A1 and SB-A2 resulted nominal loadings of 38.9 $\mathrm{KN}$ and $72.4 \mathrm{KN}$; respectively under same experimental loading conditions by modified ACI 440.2R-2017 procedure. Experimental and analysis results are subdivided into two groups namely Group A and Group B according to the reinforcement ratio in the cross-section as shown in Figure 14. In both Groups A and B, it was found that the modified analysis procedure of ACI 440.2R-2017 resulted an upper-bound value for small scale EBR-CFRP segmental beams. From Group A and B, the analysis of beams SB-A1and SB-A2 results $9.88 \%$ and $47.76 \%$ higher than segmental beams tested specimens SB5-ER-1A and SB7-ER-2A; respectively.

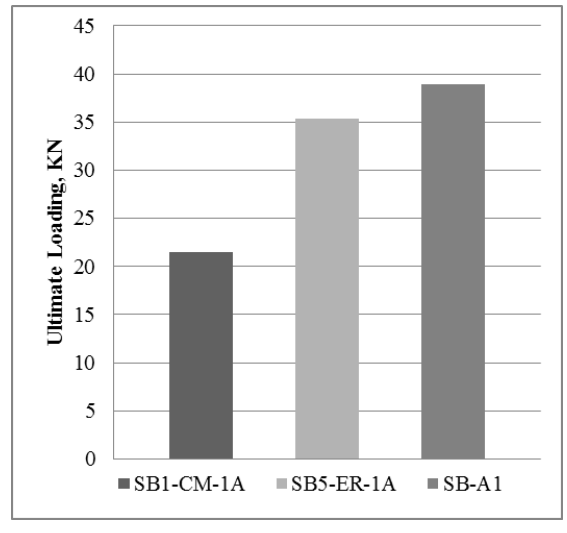

(a)

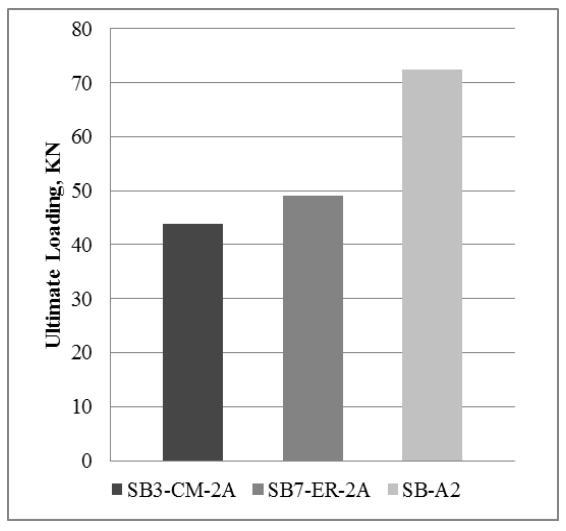

(b)

Figure 14. Experimental and analysis results (a) Group A, (b) Group B

\section{Conclusion}

Eight small scale segmental beams fabricated by means of concrete blocks and EBR-CFRP laminates were studied. The fabrication method of segmental beams found to be effective and sustain considerable loading for the selected cross-sectional dimensions. The results display that beams assembled by epoxy resin adhesive sustain higher loading about $64.8 \%$ and $11.87 \%$ for beams reinforced with 1A and 2A CFRP plates; respectively. Moreover, using epoxy resin have further benefits like setting faster and assembled easier than beams assembled by cementitious adhesive. Also, it is noticed that doubling EBR-CFRP area in segmental beams cross section significantly affects beams strength especially for beams assembled using cementitious adhesive as beam ultimate strength increased $104 \%$. 
Moreover, the modified procedure of ACI 440.2R-2017 was implemented for analyzing segmental beams based on two assumptions. Results from application modified procedure were found to overestimates segmental beams strength in an approximate range (10-50) \%.

For further results, more research is needed to investigate segmental beams fabricated from blocks with shear keys. Furthermore, the modified ACI 440.2R-2017 may require more assumption to obtain more accurate outcomes.

\section{References}

1. Li, G., Yang, D., and Lei, Yu. Combined shear and bending behavior of joints in precast concrete segmental beams with external tendons. J. Bridge Eng. 2013, 18, 1042-1052.

2. Saibabu, S., Srinivas, V., Sasmal, S., Lakshmanan, N., and Iyer, N. Performance evaluation of dry and epoxy jointed segmental prestressed box girders under monotonic and cyclic loading. Constr. Build. Mater. 2013, 38, 931-940.

3. Saibabu, S., Joshuva, R., Kumar, K., Lakshmikandhan, K., and Sivakumar, P. Finite element modelling of segmental model beam. Indian Concr. J.2016, Special issue, 90.

4. Pendhari, S. S., Kant, T, and Desai, Y. M., Application of polymer composites in civil construction: A general review. Compos. Struct. 2007, 84, 114-124.

5. Hanoon, Ammar N., Al Zaidee, Salah R., Banyhussan, Qais S., and Abdulhameed, Ali A. Modified Strut Effectiveness Factor for FRP-Reinforced Concrete Deep Beams. Int. J. Eng. Technol. 2018, 4.20, 485-490.

6. Abdulhameed, Ali A. Said, Abdulmuttalib I. Behaviour of Segmental Concrete Beams Reinforced by Pultruded CFRP Plates: An Experimental Study. Eng.J. accepted.

7. Codispoti, R., Oliveira, D., Olivito, R., Lourenco, P., and Fangueiro, R. Mechanical performance of natural fiber-reinforced composites for the strengthening of masonry. Composites Part B. 2015, 77, 74-83.

8. Toutanji, H., Zhao, L., Zhang, Y. Flexural behavior of reinforced concrete beams externally strengthened with CFRP sheets bonded with an inorganic matrix. Eng. Struct. 2006, 28, 557-566.

9. American Concrete Institute, Guide for the design and construction of externally bonded FRP systems for strengthening concrete structures (ACI 440.2R-2017), ACI, Farmington Hills, MI, 2017.

10. Sika Group, Sika CarboDur Plates-Pultruded carbon fiber plates for structural strengthening. Available online: https://Carbodur.pdf.

11. Sika Group, Sikadur-30 LP- Thixotropic adhesive for bonding reinforcement. Available online: https://Sikadur-30LP_PDS.pdf.

12. Don Construction Products, Cemfix W-High performance, deformable cementitious adhesive. Available online: http://CemfixW_TDS.pdf.

13. Sika Group, Sikadur-31 SBA S-02 Segmental Bridge adhesive. Available online: https://sikadur-31SBAS02.pdf. 